
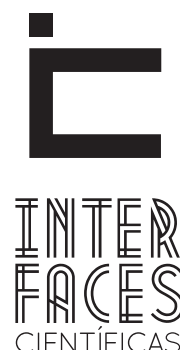

HUMANASE SOCIAIS

\title{
A INFLUÊNCIA DA SOCIALIZAÇ̃̃o RELIGIOSA E DO GÊNERO NO UNIVERSO ACADÊMICO
}

Anabela Maurício De Santana ${ }^{1}$
Cândida Margarida Oliveira Matos²

\section{RESUMO}

Este artigo analisa a reprodução de relações de gênero no âmbito acadêmico, considerando a religiosidade, possibilitando uma reflexão sobre a transição da mulher da esfera privada para a esfera pública, mediante seu ingresso na universidade. Abordamos o papel da educação na sociedade, identificando as profissões que incorporam uma imagem valorativa calcada na socialização religiosa e no gênero, explicitando um mito com relação a algumas profissões que se apresentam "para as mulheres" por envolverem “atividades condizentes” com o papel delas na família e na sociedade. Consideramos assim a permanência e reprodução de aspectos culturais na universidade. 0 artigo é baseado na pesquisa com assistentes sociais sobre a origem familiar e as motivações para a escolha profissional, realizada em Aracaju/SE em 2009.

\section{PALAVRAS-CHAVE}

Religiosidade. Gênero. Universidade. 


\section{ABSTRACT}

This article analyzes the reproduction of gender relations in the academic, considering the religious, enabling a reflection on the transition of the private sphere of women into the public sphere, upon their entry into university. We address the role of education in society, identifying occupations that incorporate a grounded evaluative image in religious socialization and gender, explaining a myth regarding some professions that are presented "for women" because they involve "activities consistent" with their role in the fa- mily and in society. So we consider the permanence and reproduction of cultural aspects in university. The article is based on research with social workers on family background and motivations for professional choice, held in Aracaju / SE in 2009.

\section{KEYWORDS}

Religiosity. Gender. University.

\section{RESUMEN}

Este artículo analiza la reproducción de relaciones de género en los sectores académicos, tomando en consideración la religiosidad, es posible hacer una reflexión sobre la transición de la esfera privada de las mujeres para la esfera pública, a través de su acceso a la universidad. Abordamos el papel de la educación en la sociedad, identificando las ocupaciones que incorporaran una imagen valorativa basada en la socialización religiosa y en el género, aclarando un mito acerca de determinadas profesiones que se presentan "para las mujeres", porque implican "actividades coherentes" con su papel en la familia y sociedad. Por lo tanto, consideramos que existe la permanencia y reproducción de aspectos culturales en la universidad. El artículo se basa en la investigación con los asistentes sociales sobre la historia de la familia y las motivaciones para la elección de carrera, realizada en Aracaju/Sergipe en 2009.

\section{PALABRAS CLAVE}

Religiosidad. Género. Universidad. 


\section{INTRODUÇÃO}

Este artigo trata do ensino superior e sua relação com o gênero e a religiosidade, tendo por base a pesquisa realizada em Aracaju/SE em 2009, com trinta assistentes sociais, que responderam a um questionário abordando a origem familiar e as motivações para a escolha da profissão.

Tratar dessa questão revela a dinâmica da sociedade brasileira e como se expressam as relações sociais, especificamente de gênero, as quais permanentemente se (re) fazem, e seus componentes culturais e ideológicos, os quais necessariamente demandam funções sociais da educação formal e sua relação com o mercado de trabalho.

Para uma abordagem sobre a educação, consideramos a educação no sentido lato (informal ou social) e a educação no sentido estrito, desenvolvida pela instituição escola, que abordamos aqui como universidade.

Ao explorarmos alguns fenômenos sociais, não podemos deixar de situá-los numa sociedade capitalista que prima pelas desigualdades advindas de seu modo de produção e dos conflitos que irrompem com a busca pela igualdade, tampouco ignorarmos os valores que se desenvolvem nessa sociedade caracterizada pelo autoritarismo.

Entendemos assim que a educação é transversal a toda a sociedade; apresenta-se no organismo social, tendo como viés a sociedade, a história, a religião, o trabalho, o gênero, dentre outros. A família, a Igreja, a comunidade, os meios de comunicação, a escola, são algumas das faces da educação; algumas mais enfatizadas que outras, devido ao papel determinante na sociedade, mas em níveis diferentes, importantes e presentes na vida do indivíduo e no seu processo de socialização.
A história da educação no Brasil4 mostra períodos profícuos que marcaram o sistema educacional atual. Desvenda os caminhos que foram sendo traçados desde a colonização, pontuado por mudanças socioeconômicas, políticas e ideoculturais que influíram no significado social do fenômeno em questão e, principalmente, revela que a educação sempre esteve a reboque da produção, empobrecendo seu papel político, sua fecundidade de gerar cidadania.

Nas últimas décadas, Estado e empresários vêm dando relevância à educação enquanto fator diferencial na produtividade e lucratividade. Do mesmo modo, é preciso perceber a educação como elemento causal que não deve ser preterido, mas sim imprescindível na construção do conhecimento.

Além da ênfase na política de educação, o enfoque epistemológico, na concepção e no processo cognitivo da educação, faz-se necessário, demonstrando que mais que quantificar dados, é importante entender a complexidade do processo educativo, seu dinamismo, suas possibilidades, num processo investigativo, o que revela o mundo da educação e sua importância na construção das identidades.

No espaço educacional se faz presente uma importante leitura do papel que a escolarização cultivou na sociedade, no que concerne à formação de quadros profissionais necessários à economia, como também seu papel ideológico de manutenção da ordem. A educação formal e informal é, pois, reflexo da realidade em que se insere, contribuindo, concomitantemente para a composição dessa mesma realidade. É evidente a importância desta na construção de uma sociedade democrática.

No entanto, concernente ao ensino formal, a escola brasileira está distante dos problemas enfrentados

4. Cf., entre outros, o livro de Luis Antonio Cunha, Educação, Estado e Democracia no Brasil, e de Eliane Lopes (org), 500 anos de Educação no Brasil. 
cotidianamente pela população, prima pelo descaso com a realidade de um povo excluído, reproduz e aumenta as diferenças entre classes, gênero e raças, compactuando com uma sociedade desigual, configurando-se também como um sistema excludente.

A sociedade hodierna, mediante políticas públicas, vem propondo intervenções diferenciadas em relação a posições econômicas aliadas ao debate étnico-racial, do qual depende um grande contingente de jovens brasileiros. É uma discussão polêmica que evidencia um despertar da sociedade, concernente à inserção de minorias no âmbito universitário. Todavia, a questão é maior e mais profunda, inclui desde o ensino infantil, passando pelo ensino fundamental, para então aportar na universidade, que reflete os aspectos de ordem social, econômica e cultural de cada sociedade.

Dessa reflexão, é oportuno salientar que antes de tudo, a escola é um espaço onde emanam ideias, dúvidas, hipóteses e tentativas que objetivam encontrar respostas. Entretanto, ela não é o único universo responsável pelas transformações sociais e ideológicas, mesmo sendo este um espaço privilegiado de debates sobre a construção da prática reflexiva de qualquer profissão. Igualmente, a ela devem se juntar outras instituições (a Igreja, a família), que por sua vez também têm promovido reflexões acerca do papel social da mulher e sua participação política e histórica.

\section{GÊNERO E EDUCAÇ̃̃O RELIGIOSA NO UNIVERSO ACADÊMICO}

A família e a Igreja são instâncias importantes no processo de educação e estão implicitamente inseridos na vida de cada indivíduo, visto que o processo de construção de estruturas mentais tem início na família e depois é complementada na Igreja e na escola, estendendo-se para a vida profissional, demonstrando a relevância dessas instituições sociais nas disposições dos indivíduos.
A família configura-se como uma das mais importantes instituições que desenvolve a educação informal. Ela socializa os seus componentes, desenvolvendo comportamentos que muitas vezes se apresentam contraditórios na negação ou na aceitação da ordem social.

Estímulos e valores são absorvidos pelo homem e pela mulher e compõem respectivamente as identidades. No caso das mulheres, eles criam uma ambivalência que as leva a ajustarem-se a carreiras tipicamente femininas, pois ao serem preparadas para o casamento e a maternidade, as jovens acabam optando por profissões que não lhes dificultem os papéis que serão desempenhados posteriormente; ao mesmo tempo o mercado de trabalho reforça valores sociais e induzem as mulheres a "carreiras próprias ao sexo feminino” (BLAY apud HECKERT, 1991, p. 22).

A divisão sexual das carreiras ocorre porque o gênero está associado a noções socialmente construídas de masculinidade e feminilidade; ou seja, a distinção entre sexo e gênero é fundamental, pois muitas diferenças entre homem e mulher não são de origem biológica. Logo se observa que o gênero é um conceito socialmente criado que atribui aos homens e às mulheres papéis sociais e identidades distintas. 0 gênero dá significado às diferenças que são produzidas socialmente, e mediante o processo de construção do gênero, a sociedade lança mão de ideias sobre ser homem e ser mulher e o que é próprio de cada sexo. Contudo, a sua simbolização cultural, além de macular os sexos, macula o social, o religioso e o político.

Assim, é nessa sociedade que tem no trabalho o princípio das relações sociais e que reproduz relações de dominação, opressão e exploração, que se constroem as profissões diferenciadas para o homem e para a mulher. Trata-se da divisão sexual do trabalho como reflexo dos condicionamentos econômicos, sociais e culturais.

As estruturas sociais autoritárias do homem sobre a mulher e filhos na família são uma construção social que influi na divisão sexual do trabalho, bem 
como na formação dos indivíduos na sociedade, os quais reproduzem de forma inconsciente a dominação masculina, refletindo na configuração de papéis do homem e da mulher.

A mulher no espaço privado imprime nos filhos características de personalidade, contribuindo na assimilação de papéis institucionalizados, pois ela é responsável pela educação da prole. Assim, os afazeres domésticos compõem saberes (cuidar, organizar, educar, orientar) que ajudam na definição de escolhas profissionais e na mobilidade dentro do universo profissional.

Dentro desse panorama, um aspecto que merece aprofundamento é o desempenho da mulher em vários papéis, já que esta questão incide diretamente em sua vida pessoal e carreira profissional.

Nesse sentido, é importante ressaltar que a divisão sexual do trabalho estabelece os Estados de Bem-Estar Social, sendo às mulheres atribuídos os papéis de mães, cuidadoras, esposas e trabalhadoras do lar, mesmo quando se encontram no espaço público (mercado de trabalho), administrando as duplas e/ou triplas jornadas atribuídas a elas e que, ironicamente, as tornam heroínas ou abnegadas, enquanto aos homens cabe o papel de provedor de suas famílias por meio do trabalho remunerado.

O cumprimento das diversas "funções femininas" faz parte da busca pela conciliação do ser mãe, esposa, profissional, dona de casa, estudante e da ideia que carrega de ser mulher (práticas de ajuda, de cuidado e educação), que em determinados momentos produz uma ambiguidade e uma ambivalência, que coexistem nas mulheres e geram sentimentos e posturas contrárias que lhe causam angústia e frustração (OLIVEIRA, 1993).

Ainda que profissões masculinas e femininas não tenham hoje uma fronteira rígida, o gênero continua sendo responsável por escolhas profissionais, perdurando a divisão sexual das profissões que Rosemberg
(1992, p. 64) chama de "guetização das carreiras"; isto é, o reconhecimento de uma classificação, denominando as carreiras femininas (humanas), mistas e masculinas (técnicas).

Diante do quadro de discriminação e opressão recorrente no meio familiar, cabe salientar que o poder público deve criar e disponibilizar condições necessárias para o exercício pleno dos direitos à vida, à saúde, à alimentação, à educação, à segurança, ao acesso à justiça, à convivência familiar, dentre outros, de forma a garantir os direitos das mulheres, com políticas que as resguardem de: discriminação, exploração, violência, negligência, crueldade e opressão. Logo, as igualdades de gênero devem estar no cerne das políticas de governança, em que as mulheres devem ter espaço para contribuir ativamente na elaboração e aplicabilidade das políticas sociais.

Pertinente ao gênero está a educação religiosa, pois as profissões identificadas como femininas estão associadas a valores humanitário-religiosos que se coadunam ao papel associado à mulher no âmbito privado, tais como o cuidado, o altruísmo, a educação, a abnegação, configurando a Igreja como uma instituição que exerce influência sobre as mulheres e que congrega o habitus ${ }^{5}$.

Segundo Torres (2002, p. 55), “por meio de sermões e discursos normatizadores, a Igreja criou uma rede de tabus, reforçando a concepção de mulher como um ser frágil, dependente e submisso, cabendo- lhe o papel de zelar pelo bem-estar do marido, gerar filhos e educá-los”.

Esse processo de internalização, pelo indivíduo, de condições históricas e sociais vivenciadas ao longo de sua trajetória pessoal e social está presente no campo religioso que, segundo Bourdieu (1997), age como

5. O termo habitus é adotado como um princípio de disposições adquiridas pela experiência, portanto variáveis segundo o lugar e o momento e ajustáveis a uma infinidade de situações possíveis, que lhe conferem um caráter imprevisível (BOURDIEU, 2004). 
sistema de possibilidades e de impossibilidades de expressão que proíbe ou encoraja processos psíquicos diferentes daqueles do mundo ordinário.

Assim sendo, a família e a Igreja se apresentam como importantes instituições responsáveis por motivações de escolhas profissionais e consequentemente pela inserção na universidade.

A associação entre profissões femininas e atividades domésticas, comunitárias e assistenciais do grupo familiar pode ser usada como parâmetro de escolha para que os candidatos que possuam sentidos e valores religiosos e de gênero apostem neste como vocação para eleger uma profissão, conforme indicam as assistentes sociais entrevistadas.

Desse modo, o exercício das funções educativas e de cuidados imputados às mulheres persiste indicando a feminização de algumas profissões (como enfermagem, educação, psicologia, além do Serviço Social) e sua atribuição e identidade na sociedade, que as apresentam como profissões valorativas. A feminização refere-se ao significado e valor social da profissão na sociedade, dando-lhe um caráter qualitativo. Já a feminilização refere-se ao aumento do peso relativo do sexo na composição de uma profissão (aspecto quantitativo) como assim expressa Yannoulas (2000).

Algumas profissões como as do Serviço Social e Enfermagem são historicamente constituídas por mulheres. O Serviço Social, como nos indica Simões (2005), desde 1960, independentemente da região do país, é composto majoritariamente por mulheres. Já outras profissões se transformam em "profissões femininas”, como é o caso da pedagogia6, que era do domínio masculino e aos poucos foi se alterando, principalmente pela influência do movimento femi-

6. O magistério, na sua origem, foi ocupado por homens e à medida que as mulheres invadiram este espaço, inicia-se um processo de regulamentação dessa área profissional para conformá-lo ao comportamento que se esperava da mulher. LOURO, Guacira. Mulheres na sala de aula. In: História das MuIheres no Brasil. Campinas: Unesco/Contexto, 1997, p. 443-481. nista; mas, a prática social alia-se, de forma bastante funcional, à necessidade de profissionalização e de inserção da mulher no mercado de trabalho; e o exercício das funções educativas, de cuidados imputados às mulheres, persiste nos dias atuais. Assim, observamos que o Serviço Social mesmo quando é regulamentado como profissão, não deixa de estar associado à ajuda e consequentemente a papéis femininos, compondo a identidade profissional (GENTILLI, 1997).

A noção da profissão que as assistentes sociais entrevistadas apresentam, antes de ingressarem na universidade, ratifica o exposto anteriormente, visto que o serviço social é tomado como uma profissão de ajuda, auxílio, orientação, execução de obras sociais, numa perspectiva social (caridade, filantropia, assistência, dignidade) para os indivíduos ou grupos pobres, desfavorecidos, carente e pessoas com necessidades sociais (86\%). Apenas um grupo menor (4\%) fez referência ao mercado de trabalho ou não soube precisar um conceito (10\%).

Assim, apesar dos esforços da categoria dos assistentes sociais de caracterizar a profissão como mediadora entre as classes que cumprem um papel político, a ideia de ajuda ou de convivência com o outro é recorrente na profissão, tornando-se um indicador para os candidatos a uma "profissão de atributos femininos".

Concernente a esse resultado, o Serviço Social atual eleva-se ao patamar profissional, mas permanece com uma imagem de profissão feminina associada à ajuda e, mais especificamente, ao sentimento religioso de amor e cuidado ao próximo ou aos mais carentes, apresentando assim uma carga religiosa, conformando o perfil de algumas profissões consideradas femininas.

Os dados coletados com as assistentes sociais novamente ratificam essas informações, visto que as profissionais tiveram uma recorrente referência religiosa dos pais. A socialização religiosa das profissionais pode ser atestada nas frequências semanal (34\%) e mensal (26\%) - apenas 13\% afirmaram ir à Igreja só 
em eventos -, mediante uma formação religiosa diversificada na infância e juventude, seja por meio de catecismo, missas, grupos de jovens, colégios religiosos ou trabalhos beneficentes típicos do catolicismo (69\% são católicos), sendo indicada ainda a religião protestante (10\%), espírita e evangélica (com 4\% cada).

Atestamos, portanto, que a educação religiosa é um aspecto marcante na origem familiar das profissionais entrevistadas, configurando-se num total de $87 \%$ das famílias das assistentes sociais. Com base na orientação religiosa dos pais, os descendentes tendem a seguir esta direção, salvo os casos em que um dos dois (pai ou mãe) não é religioso e influencia na religiosidade dos filhos - geralmente o pai é agnóstico, já que a religião é mais afeita à condição do ser mulher.

Essa assertiva é identificada pela diferença entre a religiosidade dos pais e a das mães das assistentes sociais. Mais da metade dos pais das entrevistadas é católica (69\%) e apenas 10\% não têm religião. Do total de pais, $61 \%$ só vão à igreja em eventos, e apenas $22 \%$ têm uma frequência semanal. As mães se mostraram mais religiosas (74\% são católicas) que os pais, reforçando a relação da religião com gênero, assim como a frequência é maior (mais de uma vez por semana, (39\%), e semanal, (17\%). Apenas 26\% das genitoras frequentam a Igreja em eventos.

A educação religiosa familiar ajuda a cultivar o desejo de servir ao próximo e subsidia no direcionamento de uma escolha profissional para as mulheres que se autoidentificam com o Serviço Social (dentre outras profissões) visto como uma profissão de assistência aos mais carentes conforme salienta Simões (2005).

Conforme Canda e Furman (1999, p. 9 apud Simões, 2000, p. 97), os principais motivadores para a escolha do curso de Serviço Social estão ancorados em "um senso de mandato para o serviço, um desejo pessoal de promover a justiça social e uma busca por autorrealização"; ou ainda, como afirma lamamoto (1998, p. 65), por valores nobres, “de fundo religioso, político e humanista". Consequentemente, a "identidade e os valores religiosos permanecem relevantes como indicadores do que é a profissão e, portanto, como a referência para a escolha profissional” (SIMÕES, 2005, p. 96).

Todavia, esses aspectos não se apresentam de forma consciente nas motivações da escolha profissional, pois depende de uma diversidade de fatores motivacionais e socioculturais, determinantes nas carreiras profissionais. Além do gênero e da socialização religiosa, o valor simbólico concorre nas projeções que se fazem da profissão, referentes ao retorno social e econômico que esta possa garantir. Assim sendo, avaliamos que a inserção na universidade é condicionada por variáveis que só ganham sentido quando associadas entre si, formando uma predisposição que estrutura a escolha de uma profissão.

Ao pensar a educação e especificamente a universidade, faz-se relevante considerar a cultura de cada sociedade, pois, como podemos constatar, o processo de construção de estruturas mentais tem início na família e depois é complementada na Igreja e escola, estendendo-se para o âmbito acadêmico e para a vida profissional, demonstrando a relevância dessas instituições sociais nas disposições dos indivíduos.

\section{CULTURA E UNIVERSIDADE: ALGUMAS CONSIDERAÇÕES SOBRE O GÊNERO NA ACADEMIA}

A universidade, como instituição que pretende a cidadania, deveria ser o lócus onde se desenvolve uma relação de igualdade. Deveria também propiciar condições para formar profissionais competentes e eticamente comprometidos com a democracia. Desse modo, ela tem como desafio suprimir os obstáculos que grande parte da população enfrenta ao buscar uma educação de nível superior. 
Numa primeira aproximação com o mundo universitário, pode-se afirmar que esse é o local em que se adquirem conhecimentos suficientes para o ingresso no mundo do trabalho. Ao relacionar-se com a sociedade, a universidade está comprometida com a preservação da cultura e valores de um povo.

No entanto, mediante um olhar mais profundo, é possível asseverar que cabe à universidade função mais complexa e contraditória. 0 compromisso com a transformação da sociedade e a inovação são proposições inerentes à universidade e que convivem contraditoriamente com a preservação do patrimônio do povo.

\section{Como nos diz Wanderley sobre a universidade,}

[...] a princípio, seria um lugar apropriado para o exercício pleno da cidadania, e mesmo de afirmação do sujeito, ao defender o pluralismo do pensamento, ao suscitar medidas para assegurar relações fraternas numa comunidade universitária, ao oferecer condições para formar profissionais competentes e com uma ética apurada (WANDERLEY, 2000, p. 156).

Belloni (1992), quando se refere às funções sociais da universidade, cita, entre outras, a função de gerar saber comprometido com a justiça, porque é a base das relações entre os homens; um saber comprometido com a igualdade porque é a base da estrutura social e inerente à condição humana.

Observamos, no entanto, que a universidade tem reproduzido as relações desiguais e preconceituosas presentes na sociedade moderna. 0 caso Geyse Arruda7, dentre outros, o qual teve grande repercussão na mídia, ilustra bem que o ingresso e permanência de homens e mulheres na universidade não modificam a percepção de que os espaços femininos e masculinos devem ser diferenciados, mesmo porque a construção

7. Geyse Arruda, estudante da Uniban (Universidade Bandeirante de São Paulo), foi agredida verbalmente na universidade por mais de 500 alunos, no dia 22 de outubro de 2009, ao se apresentar com um minivestido cor de rosa. A estudante de 20 anos teve que contar com escolta policial para sair ilesa da universidade. Devido aos fatos, a direção da universidade expulsou a aluna e depois retificou a expulsão graças à repercussão internacional que o caso alcançou. dos estereótipos masculino e feminino dá-se ao longo da história de cada indivíduo no processo de educação e socialização e são fortalecidos nas instituições sociais, perpetuando a discriminação.

Em pesquisa realizada em 2002 na Universidade Tiradentes8, foi possível identificar que no âmbito acadêmico os discentes reeditam a identidade feminina, calcada nos papéis de mãe, esposa cuidadora do lar, assim como a relação afetivo-sexual se expressa de forma conflituosa e dicotômica, ora presente na sacralidade e virtuosidade feminina, ora no profano e libertino, o que em parte explica o tratamento dado ao caso anteriormente citado.

Da mesma forma que o meio acadêmico reproduz os estereótipos da mulher mãe ou da mulher dissoluta, perpetua também a estratificação sexual das carreiras, pois o que move as mulheres para determinadas profissões é o sentimento de vocação, de realização pessoal ou de outras vantagens simbólicas (BLAY apud HECKERT, 1991, 33).

\section{BREVES APRECIAÇÕES CONCLUSIVAS}

Fazendo uma rápida reflexão histórica, descobrimos que a mulher brasileira demorou a ingressar na universidade, e quando o fez em grande escala, procurou as carreiras tidas como femininas, constituindo-se esta opção em virtude dos limites impostos pela sociedade à mulher, definidos através de estereótipos: aos homens, carreiras de valor social, carreiras de produção, que contribuem na economia; para as mulheres, carreiras voltadas para a humanização, que não envolve mando; de menor valor social.

Algumas áreas de atuação profissional identificadas como femininas - psicologia, letras, pedagogia, enfermagem, artes, nutrição e Serviço Social - são

8. Os resultados da pesquisa estão publicados na revista Fragmenta com o título "Sombras do Espelho: as imagens sobre a mulher construídas por estudantes universitários em Aracaju/SE”. 
desvalorizadas, têm baixa remuneração no mercado de trabalho e apresentam, em alguns casos, peculiaridades da identidade feminina, como por exemplo um caráter organizativo fraco da profissão.

Por conseguinte, não é suficiente a expansão da educação formal feminina, nem a igualdade de oportunidade de acesso e de permanência de homens e mulheres no ensino superior para a superação das diferenciações entre homens e mulheres. Ao ignorar todas essas questões, conserva-se um sistema discriminador que retrata a divisão sexual do trabalho presente na sociedade brasileira.

Nesse processo, há de se averiguarem os vários elementos que se entrecruzam e caracterizam uma sociedade e um sistema de ensino excludente. Outras questões pertinentes, não menos importantes, podem ser citadas, compondo o quadro do ensino brasileiro: as diferenças étnico-raciais, regionais, religiosas e a dicotomia entre público e privado das instituições.

Todas essas questões estão presentes no ambiente universitário, reforçando valores culturais e se concretizando na dinâmica dos cursos universitários, imprimindo peculiaridades possíveis de serem percebidas nesse universo. A dinâmica dos cursos de nível superior, os quais se apresentam na sociedade como naturalmente femininos, é forjada pela divisão sexual do trabalho, revelando a condição da mulher no meio universitário no Brasil e a visão "ingênua e discriminatória" difundida na sociedade quanto à escolha profissional e que restringe a liberdade da mulher quanto a sua futura profissão (FERRETI apud HECKERT, 1991).

A educação familiar, religiosa e universitária reproduz, pois, as relações de gênero e suscita o debate sobre o respeito ao diferente e à pluralidade, a vida universitária da mulher brasileira, bem como a discriminação social que esta sofre e que é levada para o âmbito profissional, explicitada na baixa remuneração, pouca oferta de empregos e desprestígio profissional.

\section{REFERÊNCIAS}

BELLONI, Isaura. Função da universidade: notas para reflexão. In: Coletânea C.B.E. Universidade e Educação, Campinas: Anped, 1992. p. 71 - 78.

BOURDIEU, Pierre. Coisas Ditas. São Paulo: Brasiliense, 2004.

BOURDIEU, Pierre. As contradições da herança. In: A Miséria do Mundo. Petrópolis, Rio de Janeiro: Vozes, 1997 (a). p. 587 - 691.

BOURDIEU, Pierre. A dominação masculina em questão, In: LINS, Daniel (Org). A Dominação Masculina Revisitada. Tradução: Roberto Leal Ferreira. Campinas, SP: Papirus, 1998, p.11-26.

CASTELLS, Manuel. O Fim do Patriarcalismo: movimentos sociais, família e sexualidade na era da informação. In: O Poder da Identidade. São Paulo: Paz e Terra, 1999. p.231-356.

CUNHA, Luiz Antônio. Educação, Estado e

Democracia no Brasil, 3 ed. São Paulo: Cortez, 1999.

GAMA, Andréa Souza. As contribuições e os dilemas da crítica feminista para a análise do Estado de Bem-Estar-Social. In: SER Social: Programa de Pósgraduação UNB, Departamento de Serviço Social. Brasília, v. 10, n. 22, jan./jun. 2008, p. 41-68.

GENTILLI, Raquel de Matos L. A prática como definidora da identidade profissional do Serviço Social. Revista Serviço Social \& Sociedade. São Paulo: Cortez, ano XVIII, n. 53, 1997, p. 126-144.

HECKERT, Sonia Maria R. Identidade e mulher no Serviço Social. Serviço Social \& Sociedade. São Paulo: Cortez, ano XII, n. 36, 1991. 
IAMAMOTO, Marilda V. 0 Serviço Social na profissional. São Paulo: Cortez, 1998.

LOPES, Eliane, FILHO, Luciano, VEIGA, Cynthia (orgs.), $\mathbf{5 0 0}$ anos de Educação no Brasil. 2. ed. Belo Horizonte: Autêntica, 2000.

LOURO, Guacira. Mulheres na sala de aula. In: História das Mulheres no Brasil. Campinas: UNESCO/ Contexto, 1997. p. 443-481.

MATOS, Cândida M., PEREIRA, Jesana B., TAVARES, Márcia S. Sombras do Espelho: as imagens sobre a mulher construídas por estudantes universitários em Aracaju/SE. In: Fragmenta: revista científica. Aracaju: Universidade Tiradentes, 2005. p. 21-35.

OLIVEIRA, Rosiska de. A construção de contrários: lógica do privado/lógica do público. In: Elogio da diferença: o feminismo emergente. São Paulo: Brasiliense, 1993. p. 75-90.
ROSEMBERG, Fúlvia; AMADO, Tina. Mulheres na Escola. In: Cadernos de Pesquisa. São Paulo: Fundação Carlos Chagas, 1992, n. 80, p. 3-21.

SIMÕES, Pedro. Assistentes Sociais e Religião: um estudo Brasil/Inglaterra. São Paulo: Cortez, 2005.

TORRES, Iraildes Caldas. As Primeiras-damas e a Assistência Social: relações de gênero e poder. São Paulo: Cortez, 2002.

WANDERLEY, Luiz Eduardo. Educação e cidadania. Serviço Social \& Sociedade n. 64, ano XXI. São Paulo: Cortez, jul 2000.

YANNOULAS, Silva. Notas para a integração do enfoque de gênero na educação profissional. In: VOGEL, Arno (Org). Trabalhando com a Diversidade no Planfor: raça, cor, gênero e pessoas portadoras de necessidades especiais. São Paulo: UNESP, 2000, p. 78-91.
Recebido em: 14 de Janeiro de 2015

Avaliado em: 8 de Maio de 2015

Aceito em: 18 de Maio de 2015
1. Mestrado em Educação pelo Núcleo de Pós Graduação em Educação da
Universidade Federal de Sergipe (2014), graduação em Serviço Social pela
Universidade Tiradentes (2007), especialização em Didática e Metodologia
do Ensino Superior pela Faculdade São Luís de França (2009). Participa do
Grupo de Pesquisa do CNPq: “Educação, Formação, Processo de Trabalho e
Relações de Gênero" e do Grupo “Gênero, Família e Violência” - UNIT. As-
sistente Social do Núcleo de Práticas Jurídicas da Universidade Tiradentes
e Professora Tutora do Centro de Educação Superior a Distância da Univer-
sidade Federal de Sergipe. E-mail: anab.santana@hotmail.com
2. Mestra em Sociologia pela Universidade Federal de Sergipe, graduada em
Serviço Social pela Universidade Católica do Salvador/BA. Professora do Cur-
so de Serviço Social da Universidade Tiradentes. E-mail: camom@oi.com.br 